\title{
'Remembering' Absent and Recent Pasts Through Photographs: Young Eritrean Women in New Zealand
}

\author{
Louise Humpage \\ University of Auckland \\ I.humpage@auckland.ac.nz \\ Jay Marlowe \\ University of Auckland \\ im.marlowe@auckland.ac.nz
}

\begin{abstract}
This article presents a Photovoice project that explores the narratives of five young women of Eritrean heritage living in New Zealand. The photographs taken by the women suggest that their current individual and collective identities are mediated by two different kinds of 'memories': 'post-memories' of an absent past in their ancestral country that they were too young to experience, which build identity and belonging at the collective level, and 'autobiographical memories' of recent, lived experiences which remind participants of their individual achievements since resettlement and/or help them articulate a future in New Zealand.
\end{abstract}

\section{Introduction: Identity, memory and belonging}

This article explores the narratives of five young women of Eritrean heritage who resettled in Auckland, New Zealand as children or were born and raised there. It finds that 'memories' are used to navigate two social worlds: that of their ancestral country and New Zealand. Migration always requires a fine and strategic balance between retaining key aspects of one's culture alongside adopting new ways of being and thinking in the new settlement environment. A vast literature indicates the difficulties of achieving this balance, particularly amongt young people whose personal experience of the 'old' world may be limited or non-existent and is thus mediated by the experiences and memories of parents and older family members (Berry, Phinney, Sam, \& Vedder, 2006; Brough, Gorman, Ramirez, \& Westoby, 2003; Humpage, 2009). 
Forced migration adds another dimension to these dynamics because there has been limited or no active choice to migrate to a particular host country, which often enhances nostalgia and longing for a homeland that may no longer exist outside of an individual's or group's memory (Rosińska, 2011). Importantly, this may be true for a person who is not technically a 'refugee', that is, someone who has been assessed and accepted as having a well-founded fear of persecution according to the United Nations High Commissioner for Refugees (1951) Convention Relating to the Status of Refugees. For instance, a person may have experienced forced migration but been accepted for resettlement under family reunification criteria, or born in a country of settlement to parents who arrived as refugees. Experiences of displacement, political violence and upheaval are nonetheless a powerful and enduring part of the lived experiences of those of refugee background, no matter which immigration pathway was taken. Previous research has identified the significant hurdles faced by refugees as they make New Zealand 'home' (see, for example, Bloom, O’Donovan, \& Udahemuka, 2013; Humpage, 2009).

This research utilises the Photovoice method, which has been found to offer space for people from refugee backgrounds to identify affirmative experiences associated with migration, not only deficits and adversities (Fozdar \& Hartley, 2012). Informed by Freire's influential pedagogy on critical consciousness, the Photovoice approach creates opportunities for and gives voice to participants as they reflect upon their social, cultural and political histories and ascribe meanings to lived experience (Carlson, Engebretson, \& Chamberlain, 2006). Correspondingly, this article demonstrates the complex ways in which young Eritrean women negotiate and navigate the intersections between identity, memory and belonging.

Identity is neither static nor monolithic, but is rather a dynamic, complex process. While the particularities of culture and identity may shift within new settlement contexts, there is strong historical evidence of migrants maintaining long cultural traditions and an unwillingness to change beliefs, actions or perspectives after resettlement (Yuval-Davis, 2011). 'Culture' is, of course, complex, with Benhabib (2002) describing it as a horizon that recedes every time one approaches it, in that it is contestable, contextual and situated. In particular, young people "do the work of self-making and belonging without straightforward recourse to traditional and predictable identity categories, including ethnicity, and with new skills of mobility and fluidity" (Raffaetà, Baldassar, \& Harris, 2015, p. 424). 
Nonetheless, culture is often linked to ethnic identity (Anthias \& YuvalDavis, 1992) and women have traditionally been framed as embodying ethnic boundaries; the socially constructed barriers that to some degree separate and maintain ethnic communities. This is because women tend to carry responsibility for reproducing and maintaining culture. Boundaries become slippery when people no longer live within the confines of their cultural surroundings, but can be maintained through codes of both appearance and conduct. While the gendering of ethnic boundaries is often framed as inherently oppressive for women (Anthias \& Yuval-Davis, 1992), studies do show how migrant women can exercise agency in this process (D'Sylva \& Beagen, 2011; Humpage, 2000).

Women are also often framed as symbolic bearers of nationhood (Anthias \& Yuval-Davis, 1992). There is frequently considerable overlap between ethnicity and nationality, particularly in migration contexts where internal ethnic, religious and linguistic differences within a country can be blurred or misunderstood by host societies. The understanding of refugees as 'stateless' persons further complicates notions of nationhood, particularly in countries like Eritrea where, as later discussion will highlight, concepts such as 'nation' and 'state' are relatively recent constructs contextualized by the protracted thirty-year war that led to Eritrea's creation. Within resettlement contexts, where gaining residency or citizenship in the host country does not automatically result in belonging to that nation (Hoyle, 1999), multiple notions of nationhood may exist simultaneously as the past and current identities and lives of refugees intersect. Here our findings support those of recent studies of Eritreans settling across Europe which examine the complexity of identity and belonging in the settlement space (Belloni, 2016; Graf \& Thieme, 2016).

When cultural norms or everyday practices of nationalism can no longer be taken for granted, as they might have been at 'home', memory becomes extremely important to identity and belonging. Rosińska (2011) notes that in migration:

Memory plays a triple role: it is identity-forming by maintaining the original identification; it is therapeutic because it helps bear the hardships of transplantation into a foreign culture; and it is also community-forming, by creating a bond among those recollecting together. (p. 39)

We found evidence all three roles were important for our Eritrean participants in New Zealand as well as evidence of Hirsch's (1999) 
distinction between 'autographical memory' and 'post-memory'. In many cases our young participants' cultural and national identities were shaped by practices and events they had not personally experienced. In this sense, the term 'memory' is contested, at times being used to describe what we refer to as an 'absent' past, drawing on collective symbols, events and histories relating to Eritrea, where most of the participants have never lived. 'Traditional' food, clothing, events and other activities thus intersect with, and are mediated by, the new life in resettlement (D'Sylva \& Beagen, 2011; Somerville, 2008).

As the next section highlights, Photovoice has considerable potential to convey such experiences and sentiments: photographs themselves 'capture' memories and, as one of our participants noted, help us to 'remember' past events. Of course, not all memories are positive. Previous research on refugees and memory has focused heavily on the ongoing impact of trauma memories, and photographs often render refugees speechless and helpless, focusing on the universal trope of suffering (Halilovich, 2011; Mannik, 2013). Nonetheless, our data show that even memories of trauma or suffering can stimulate a sense of belonging at the collective and/or personal level.

Memories, as with any narrative, are partial and selected aspects of a particular experience that nonetheless provide powerful insights into belonging. This is a multi-layered and multi-scalar emotional attachment to feeling at 'home' which "becomes articulated, formally structured and politicized only when it is threatened in some way", such as through migration (Yuval-Davis, 2011, p. 10). Yuval-Davis (2011) argues that belonging can be constructed via: (1) social locations (sex, race, class or nation); (2) identifications and emotional attachments told through group narratives; and (3) ethical and political value systems with which people judge their own and others' belonging. The focus here is largely on the second facet, although the facets interact in complex ways and are not subsumable to each other, and the group narratives our participants draw upon are intimately linked with their Eritrean identity (although this may well reflect their specific social locations as ethnic Tigrinya, Orthodox Christians and women). Despite being young and, in some cases, born in New Zealand, the participants' photographs highlight how group narratives facilitate the 'remembering' of a cultural and national past that our participants did not themselves experience or were too young to assimilate, thus encouraging a collective sense of belonging within their national community. The photographs also, however, depict a personal sense of belonging within broader New Zealand society via memories of a more 
recent, lived past. First, however, we discuss the Photovoice methodology and our participant sample.

\section{Photovoice study design and sample}

Photovoice is a community-based research tool that aims to balance research and action, offering research subjects a say in how their experiences are represented, and potentially enabling them to influence the outcomes of policy decisions (Wang, 2006). It involves giving participants a camera to take photographs of the people and things that have meaning to them, then to explain these in their own words so that researchers can understand what each photograph represents to them. Like other researchers (for example, Wang, 2006; Green \& Kloos, 2009), we found the method allowed our young adult participants to become more active in the research process - rather than just passively responding to researcher-led questions - thus moving away from the tendency for young people to be talked about and spoken for rather than engaged in any meaningful way.

The data presented here are drawn from a wider Photovoice project asking young people (aged 18-25) from refugee backgrounds to take photographs and reflect on their lives in Auckland within several key themes: 'my home,' 'my learning experiences,' 'my employment experiences,' 'my friendships,' 'my life in New Zealand,' and 'where I feel I belong'. Participants were recruited by a third party via an Auckland organisation representing refugee communities and were trained and interviewed by a young research assistant of European descent familiar with refugee issues. Each participant was given a digital camera and took as many photos as they wished in relation to these themes over three weeks, with the total number of photos taken by each participant ranging from 40 to 150 . Having allowed the researchers to download these photos, each was discussed as part of a semi-structured interview in relation to the overall themes noted above. This study was approved by the university human participant ethics committee and participants gained informed consent from the people depicted in the photographs and agreed to allow us to present the pictures that follow.

Our sample was never intended to be representative of young refugeebackground people and, instead, focused on exploring what the narratives emerging around the photographs told us about belonging and identity among this cohort. We have chosen to focus on the data from only the young Eritrean women in order to highlight key similarities in the role of memory in culture and identity, as well as some differences that remind us that we should not homogenise the experiences even of those who come 
from the same country, ethnic group, religion, gender or age group. Given ethical concerns, we have chosen not to name our participants and allocated each an alpha identifier of $\mathrm{A}$ to $\mathrm{E}$ which we have summarised below.

\begin{tabular}{|l|l|}
\hline Participant ID & Time living in New Zealand \\
\hline A & 5 years \\
\hline B & 2 years \\
\hline C & 3 years \\
\hline D & 10 years \\
\hline E & New Zealand born \\
\hline
\end{tabular}

To put the research data in context, it is important to discuss the specific history of Eritrea and its diaspora in New Zealand.

\section{Historical context and resettlement in New Zealand}

New Zealand has resettled Eritrean refugees since the late 1990s, the result of the mass displacement of Eritrea's population following a torrid history of conflict and controversy over its borders, as well as gross human rights violations under repressive military rule. Eritrea's bordersoccupying a strategic location on the Horn of Africa, next to the Red Sea and bordering Sudan, Ethiopia and Djibouti-were established during a period of Italian colonial rule that ended in 1941. A decade of British administrative control (until 1952) was followed by the United Nations establishing Eritrea as an autonomous region within the Ethiopian federation. Ethiopia's annexation of Eritrea as a province in 1962 triggered a 30-year war for independence against Ethiopian forces, which ended when the Eritrean People's Liberation Front captured Asmara from the Ethiopian Army regime and formed a provisional government in 1991. Independence followed a referendum in 1993 (Connell, 2010; Hoyle, 1999).

Given this history, national identity-building since independence has been preoccupied with highlighting Eritrea's distinctiveness from Ethiopia. While Triandafyllidou (1998) highlights that the "identity of a nation is often defined and/or redefined through the influence of 'significant others', namely other nations or ethnic groups that are perceived to threaten the nation, its distinctiveness, authenticity and/independence" (p. 594), this can be complicated by cultural and linguistic similarities between different ethnic groups (Hoyle, 1999). Nevertheless, it may still explain why, since independence, nationalism has also been promoted through the wide use of flags and the map of Eritrea by businesses and at special family events such as weddings, while those who sacrificed their lives or limbs in the war are regarded as special symbols of the nation (Hoyle, 1999). 
Eritrea's President Isaias Afewerki of the People's Front for Democracy and Justice has been in power since 1993 and leads the country's only political party. It actively promotes a homogenous perspective of being Eritrean that reinforces the understandings of national identity noted above and limits the articulation of other narratives of national identity (Connell, 2010). For instance, Reporters Without Borders (2016) has ranked the country last in the world for press freedom over the last nine years. Despite its ratification, Eritrea's 1997 constitution has also never been fully implemented and national elections have not taken place since 1991. Human Rights Watch (2015) estimates that six percent of the Eritrean population has since fled, with an estimated 5,000 people leaving Eritrea each month (although these figures are contested, especially by the Eritrean Government). National events and memories are thus highly politicised within Eritrea and in the diaspora. Such memories are likely divided along political, ethnic and generational lines.

New Zealand's 2013 Census records 243 Eritrean people living there, a 31 percent increase since 2006 (Statistics New Zealand, 2013). Eritreans continue to arrive in small numbers under the quota refugee system and as asylum seekers, while fewer immigrate under the family reunification programme. Three of our five participants arrived under the refugee quota, while one young woman resettled under the family reunification category and another was born in New Zealand. These experiences largely mirror census data, which found that 81 percent of Eritreans living in New Zealand in 2013 were born overseas, only 62 percent of whom were born in Eritrea. Participants were all Orthodox Christians, as are half of Eritreans in New Zealand (Statistics New Zealand, 2013). Dirar (2007) notes that distinctions between Orthodox Christianity and Islam, which are dominant in Northeast Africa, have deeply rooted local traditions that have become core elements of identity within Eritrea; they are also associated with linguistic differences between the two groups (Hoyle, 1999). Participants were also all identified with the Tigrinya ethnic group, the largest in Eritrea, and, although only their Eritrean identity was specifically discussed, this may have been conflated with Tigrinya cultural norms (as is the case in Eritrea since independence). Of those participants born overseas, one had arrived ten years previously and the remainder had settled in New Zealand between three and five years ago. All participants identified with their Eritrean heritage no matter where they were born. Like the majority $(58 \%)$ of Eritreans in New Zealand, our participants live in Auckland, New Zealand's largest city. Our research focus on young women (ranging in age from 19 to 22 years) is appropriate given Eritreans in New Zealand are also 
disproportionately young (median age 23.5 years) with a fairly even gender balance (52\% women) (Statistics New Zealand, 2013).

In the following discussion, we draw upon the visual and verbal narratives of the five Eritrean women to explore the role of memory in settlement. Mannik (2013) notes that "knowledge is not stored in photographs but allotted to them through the various ways they are read and linked to ideas about memory" (p. 7). We thus took our cues from the verbal narratives of our participants, which linked the photographs to both memories of an 'absent' past and a recent, lived past. We acknowledge that, given the repressive regime in Eritrea and their ages, it is possible our participants self-censored their responses or provided simply what they thought the researchers wanted. Benhabib (2002) also notes that: "T[t]he social observer ... is the one who imposes, together with local elites, unity and coherence on cultures as observed entities" (p. 5). While we represent participant comments accurately, ultimately we selected the photographs and narratives to discuss in this article. This includes our decision not to present individual narratives in their entirety but to thematically analyse the photographs, as presented in the following two sections, using participants' accounts of their associated meanings and contexts.

\section{Making an 'absent' past present}

In popular understanding, 'memories' recall past personal experiences. This 'autobiographical memory"', however, sits alongside 'memories' that draw on other peoples' accounts that can be internalised and appropriated as one's own (Fiddian-Qasmiyeh, 2013). "Post-memory" is Hirsch's (1999) term for:

... the relationship of children of survivors of cultural or collective trauma to the experiences of their parents, experiences that they 'remember' only as stories and images with which they grew up, but that are so powerful, so monumental, as to constitute memories in their own right. (p. 8)

The photographs analysed in this section illustrate how young people, who may have been 'absent' from these experiences, are nonetheless present in Eritrean community-building processes that 'share' collective memories with young people, encouraging a sense of ethnic and national identity (Fiddian-Qasmiyeh, 2013). The photos show how everyday practices and activities can encourage a sense of national identity. For 
instance, our young participants discussed how their parents - with whom they were still living - provided visual 'reminders' of Eritrea that helped construct 'memories' of a place where these young participants had never lived or were too young to remember for themselves.

Participant A, who had lived in New Zealand for five years, took the photograph below (Photo 1), which depicts her mother crocheting in the colours of the Eritrean national flag: "This is handcraft my Mum made ... we have a bread that's cool[ed] in the jar and then we use this to cover the jar. These are the colours of our flag." In many countries, flags on public buildings are taken for granted and barely noticed as individuals go about their daily lives (Billig, 1995). But here the strong identification with the Eritrean national flag, noted by Hoyle (1999) as visually and symbolically articulating independence from Ethiopia, is reinforced daily through her mother's handiwork.

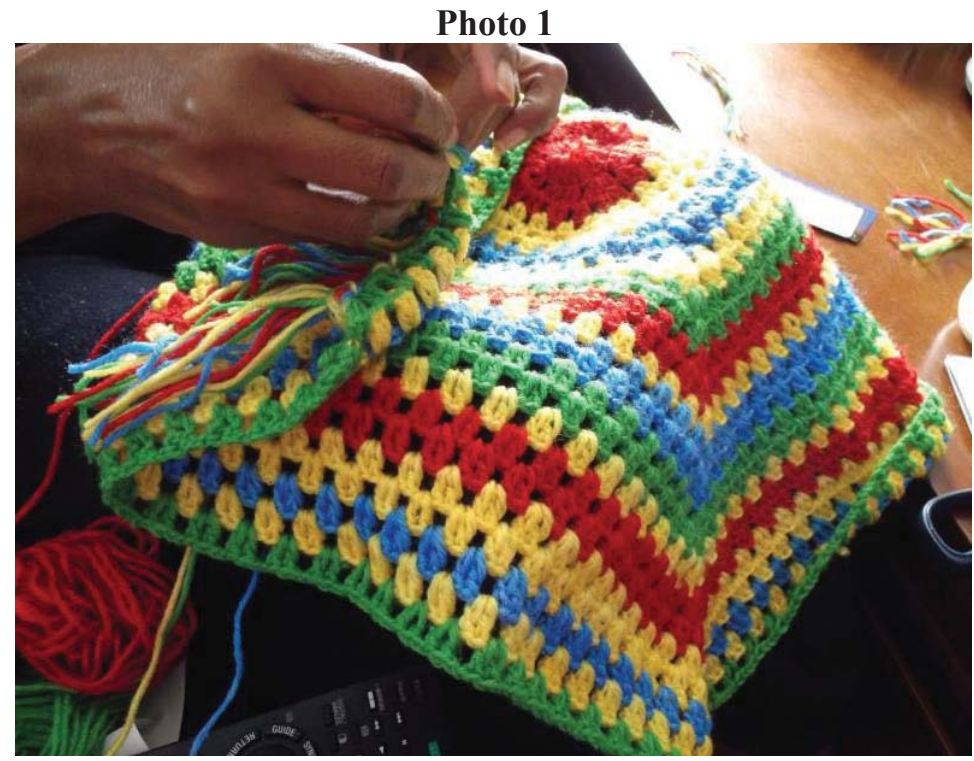

National days and events can provide an opportunity for active, collective 'remembering' of historical events that are important to national identity (Billig, 1995). This may be particularly true for those of a refugee background, given they often originate from countries torn by conflict. The Eritrean wars for independence represent one of the longest struggles on the African continent, resulting in the deaths of more than 100,000 people 
(Norwegian Refugee Council, 2014). Every year on 20 June, Eritreans mark Martyrs' Day as a national holiday to pay tribute to those who died during the conflict. Three of the five participants took photos of an event in Auckland that continued this tradition. Participant B stated:

This is Martyrs' Day. We're all originally from Eritrea, and we only got our independence like twenty-four years ago. So to get that independence we lost a lot of people. So this is to celebrate, we do it every year to celebrate their lives and stuff.

Participant B took the photograph below (Photo 2) to indicate how they commemorated martyrs' deaths by holding two minutes of silence to remember those lost. Participant $\mathrm{C}$, who arrived in New Zealand three years ago, also took several photographs like the one below (Photo 3) to demonstrate how candles are used to represent the martyrs:

There is a meaning by the light 'cos we always say that the people died for us, because they were burning down ... That box [next to the candles] is for the money. You always put money over there and send it to our country for the people for the parents who their daughters and sisters died in the struggle. So we always give them money...They give their daughters and sons to the country so that's our responsibility to help them ... It's like you have to be responsible for all those people...

This sense of responsibility ties the younger generation to those remaining in Eritrea. The same participant (C) had a further photograph

Photo 2

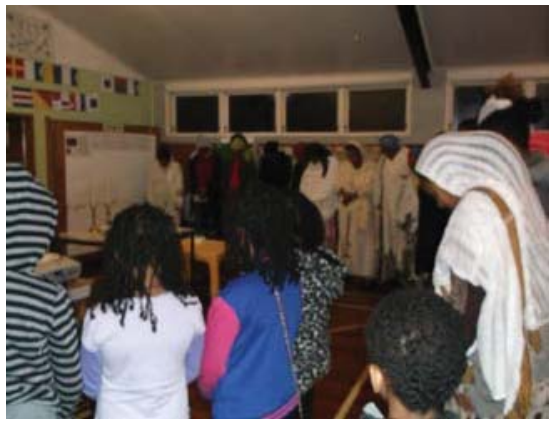

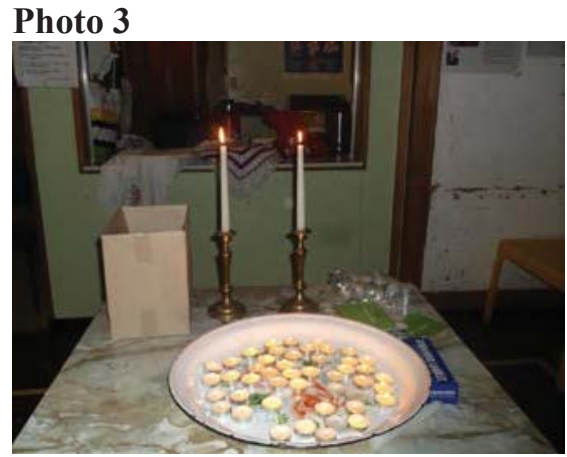

ARAS Vol.38 No.2 December 2017 
taken of herself (not featured) as she taught other young people the history behind Martyrs' Day, indicating the key role the younger generation are playing in 'remembering' an absent past. Noting that the children in other photos had been born in New Zealand she stated: "I came to New Zealand when I was 16 so I know too much, everything about Eritrea. They don't know anything."

Such findings echo Fiddian-Qasmiyeh's (2013) work with young Sahrawi refugees in Spain, where older children taught younger peers who "had not yet learnt to 'remember' the history of the conflict, the names of key places and characteristics of the [Sahrawi] homeland which come to be internalised, memorised and memorialised (and, indeed, contested) in adolescence and adulthood" (p. 637). Certainly, two other Eritrean participants (A and B), who took photos of the same candles, were a little less familiar with national history, even if they understood the candles' symbolic purpose. Participant B said: "We always light candles on Martyrs" Day. It's the 20th June and ... I don't know why we light it up but I think it's to remember them."

Fiddian-Qasmiyeh (2013) is critical of diaspora studies that assume such collective memories are transmitted to descendants with insufficient attention to "the diverse ways in which children and youth 'inherit', contest, negotiate, transmit and mobilise specific memories" (p. 632). There was certainly no indication that the young women in our study were being pressured by their parents to 'live in the past' and instead they demonstrated agency in negotiating an identity between two cultures. For instance, Participant D took photographs of relatives dressed in clothing in the colours of the Eritrean flag, noting how this 'reminded' them of their homeland, but also included a self-portrait of her window shopping for western clothes that are fashionable within mainstream New Zealand society (and indeed in many parts of Africa). There was no evidence, as found in Somerville's (2008) research, of children of migrants creating their own fashion styles reflecting both their connection to their parents' birthplace and their own country of citizenship, thus "building bridges across national boundaries" (p. 28). But this participant did not appear to consider the wearing of western clothes to be in tension with her desire to maintain Eritrean cultural practices or expectations.

National identity is, of course, not the only form of belonging important to the young women and, in many instances, this intersected with their religious identities. Participant $\mathrm{C}$, who migrated only three years ago, highlighted the importance of her Christian identity being known. Referring to a photograph of her younger sisters, she said: "There have to be crosses 
on the traditional clothes. These clothes are worn on special occasions". This embroidery provides an explicit, daily reminder of her community's religious faith. When asked if she would wear the 'traditional' dress with its crosses out every day, such as to the mall, Participant $\mathrm{C}$ replied: "Sometimes we wear 'cos we feel like 'let's show our culture". Donning such clothing reflects an internal act of pride in her religious and ethnic background that she wishes to educate others about, highlighting that socalled 'traditional' clothes and practices have relevance in contemporary New Zealand. Triandafyllidou (1998) notes that national identity can be facilitated by national community members sharing a sense of familiarity and unity when compared to an outgroup. While there is no evidence to suggest this was the explicit purpose of the young women wearing such clothes, it is likely to also have had this effect.

Importantly, religion was not something imposed by parents or community elders but was at the centre of the young women's own identities. Speaking about the photograph below (Photo 4), Participant C noted how important it was to have everyday reminders of the security their Christian faith offers today, as in past times of hardship such as when they and other Eritreans fled their country and lived in refugee camps:

That's Jesus; I just want to show it. If you go to some of the homes they have little pictures of the angels or Jesus. That's what we have to do in our house 'cos we always think that they're going to keep us safe, so we always put pictures.

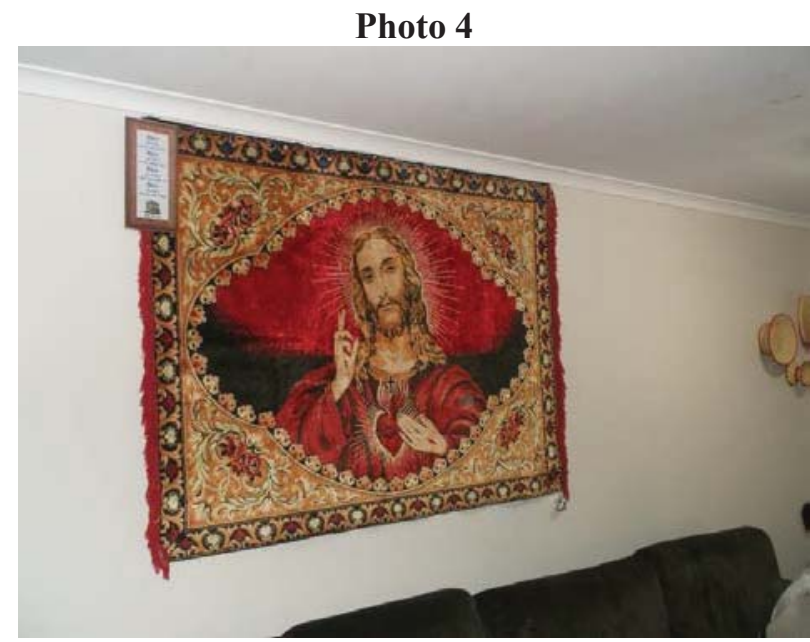


She also noted that Christian symbolism is central to her understanding of Eritrean culture:

Yeah, we are Orthodox Christians ... and our culture goes with our religion ... You have to be baptised. You have to do this and we go to church every single Sunday, like so many stuff that we do. Our religion goes with our culture, so they go hand in hand.

For this young woman, her national and religious identities were intertwined and thus mutually reinforcing.

Our participants also highlighted the crucial role of food-related practices in cultural transmission. Two of the five young women (A and E) used photographs (see Photos 5, 6 and 7, below) to illustrate the practice of making coffee and associated ethnic foods with a considerable level of detail. For instance, the first photograph below (Photo 5) was used by participant A, who had lived in New Zealand for five years, to describe the coffee bean roasting process: "See, the beans are getting darker and darker... the coffee beans are getting darker. So you roast them until they are dark", while the second (Photo 6) shows how the beans are taken off the heat and spread on a coconut tree leaf so they do not roast further. The third (Photo 7) indicates that the ground beans are then mixed with water and heated in a special pot. Later the coffee was served in small teacups with 'Eritrea' written on the side. As Humpage (2000), D'Sylva \& Beagen (2011) and others have highlighted, such cultural transmission is often highly gendered, because girls are taught by their mothers not only how to cook traditional foods but also their importance in maintaining cultural boundaries and histories.

Photo 5

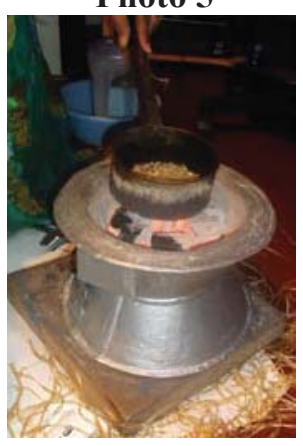

Photo 6

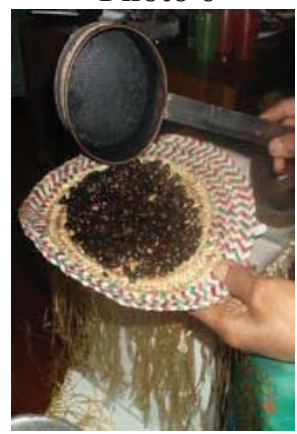

Photo 7

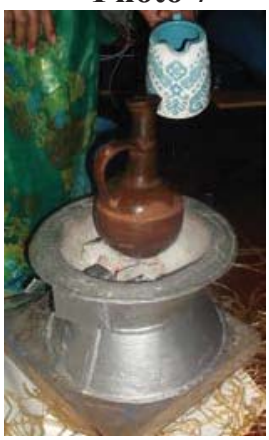


While coffee-making is also important in other cultures, the narratives of the participants $\mathrm{C}, \mathrm{D}$ and $\mathrm{E}$ suggested that the photographs were intended to represent an explicitly Eritrean national identity. The image below (Photo 8) further highlights how food plays a role in connecting the young women with the older generations. Participant D stated:

That's my Mum ... She is doing the coffee now. She is roasting it, the coffee. It's fresh coffee. That's what I have to do ... she puts water on it and she just warm it. When it boils it pops up, the coffee and then she put it here three times and then she put it down for some minutes and we just drink it. We have to do it four times.

In the process of learning the coffee-making ritual, this three-year resident of New Zealand not only learned an important Eritrean tradition, but also gave her mother the opportunity to be an 'expert' and 'teacher', roles often challenged in a resettlement context where refugee parents may struggle with the host language and new ways of life more than their children (Berry et al., 2006; Humpage, 2009).

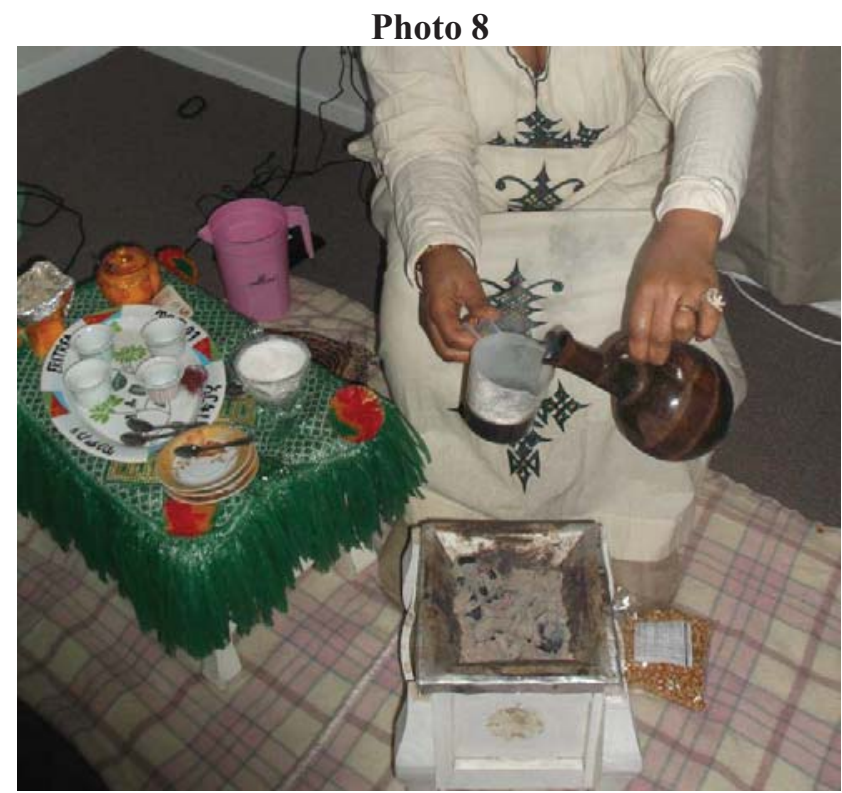


Another food that received much photographic attention was injera, the pancake-like bread that is central to Eritrean cuisine, although also eaten elsewhere. The first two photographs below (Photos 9 and 10) indicate that the focus was again on the ritualised process of making this food, which involved almost as many steps as the coffee-making! Partly this reflected a desire to help their audience - the researchers and what they more broadly anticipated might be 'New Zealanders' - understand the importance of this food to their national culture.

D'Sylva and Beagen (2011) further note the social and cultural lessons embedded within food practices. For instance, Participant B took a photo of her family eating injera, where her father gives a piece to her brother, which will then be passed to other family members starting on the right and moving anti-clockwise. This suggests that food practices can reinforce gendered power relations, but it is important to stress that other authors have found that food work can "disrupt ethnic invisibility" by situating women as key actors in cultural transmission and maintenance within communities (D'Sylva \& Beagen, 2011, p. 281). Moreover, the young woman (Participant E) who took the photos demonstrating the making and presentation of injera also included the third picture below (Photo 11) of potato chips, stating: "This is just my favourite food." This suggests a seemingly easy transition between Eritrean and New Zealand foods (and thus different representations of belonging and association) in her visual narrative.
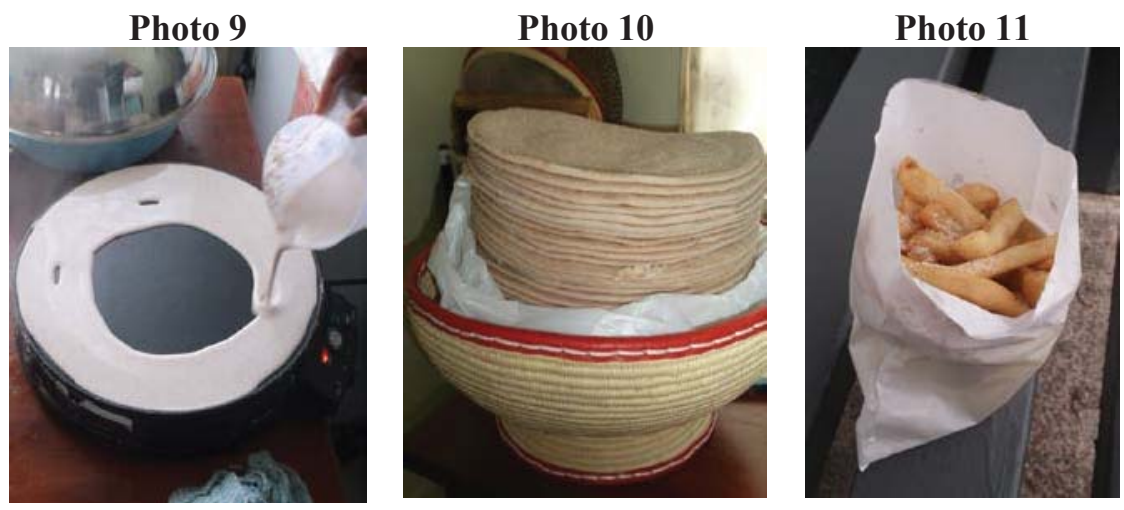

Overall, the photographs presented in this section confirm Rosińska's (2011) view that memory plays an important role in migration by encouraging a collective identity. In this case, it enables Eritrean peoples to 
bear together the hardships associated with resettlement, and facilitates a sense of national and religious identity through the collective recollection of the past and the transmission of key cultural practices to create new 'memories' among the 1.5 and second generation.

\section{Remembering a lived, recent past}

One of the main cultural functions of memory is to create social connections (Schacter \& Welker, 2016). While the last section illustrated that this was possible, even when our young refugee participants were drawing on 'post-memories', this section focuses on photographs taken by participants that invoked 'real', autobiographical memories of resettling in their new homeland and which ultimately led them to articulate a strong sense of belonging - and of a future - in New Zealand.

Given the ages of the participants, it is not surprising that discussion of life in New Zealand frequently identified school as an important place of social interaction and integration. In contrast to previous research highlighting obstacles to educational achievement and a sense of belonging at school (Brough et al., 2003; Humpage, 2009), participants only referred obliquely to negative experiences and tended to use the Photovoice methodology to reflect on the more positive aspects of their school lives. Discussing the photograph below (Photo 12), Participant C stated: "That's my school ... That's the hall—students, we were doing assembly, that's our last day of school". She liked the school because, although at 19 she was old enough to study at university, like many young people from refugee backgrounds she needed a better understanding of the New Zealand curriculum and to improve her English before pursuing her dream of training to be a nurse: "No one at the [other] high school[s] accepted me 'cos I'm old enough to go to university but [name of secondary school] they accepted me and they say if you are up to 20 we can accept you'. She acknowledged that other students were much younger and different from herself but: "They were so friendly and they were ask me, like last year of the academy and they say you should help us, you are the older ones. They are really supportive". Recalling such memories focused her attention on these social connections in a way that she did not appear to have thought about before.

The data also highlighted that achievements at school are used by young people as a measure of improvement or success since arriving in New Zealand. Remembering their early struggles with the English language and adapting to school life provides an important contrast to their present lives. When Participant A, who resettled five years earlier, was asked to reflect on 


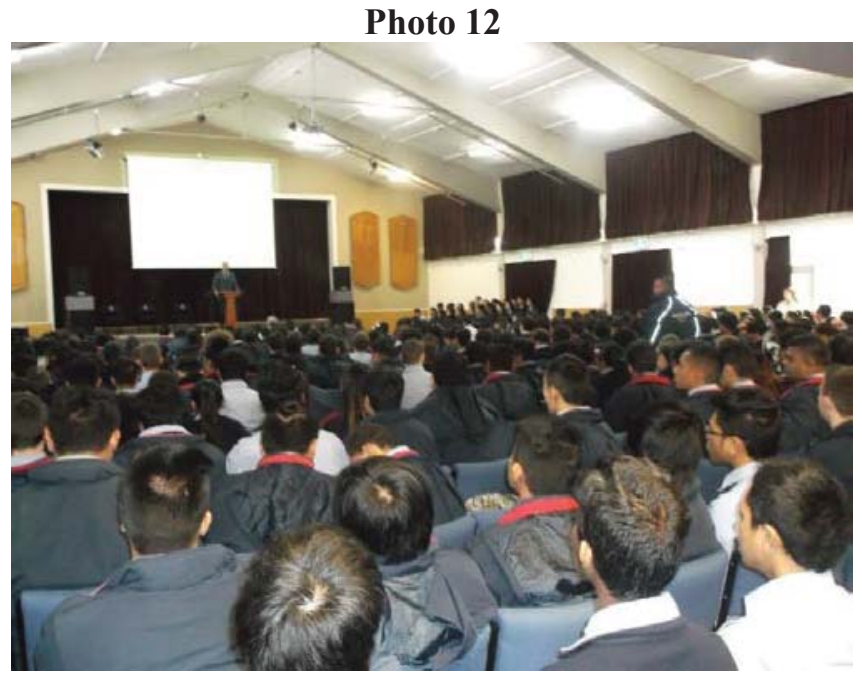

whether taking photographs for the Photovoice project was a challenge for her, she replied "no", but that it did remind her that:

... when you think of school and stuff, like we had a really hard time adjusting at school here. Because we are black we had that racial thing and then-I know English but my brothers and sisters didn't know any English - coming here, so it was really hard for them. They're finished elementary and they're in high school now. It's like we actually have achieved something now. So yeah, it wasn't there weren't any negative parts of this. It just highlights the stuff that you've achieved.

This taps into Brough et al.'s (2003) view that a distinction between "present" and "past" may be inappropriate for young people from refugee backgrounds because:

The past mingles with the present too in terms of the meanings and interpretations young people give to life events as they unfurl. Sense of success or failure, notions of freedom and independence, identity and physical and emotional security may be played out in the present, but contain salient meanings generated by the past. (p. 206) 
Indeed, Schacter and Welker (2016) note that a recent trend in cognitive and neuroscientific approaches to memory is to recognise that "human memory evolved not only to allow us to remember but also to allow us to imagine what might happen in the future" (p. 2) by recalling previously experienced events, extracting details and recombining them to simulate what might happen in their personal futures. In this sense, remembering how far they had come encouraged the participants to see what achievements might be possible in their New Zealand lives.

The New Zealand-born Participant E took a photo of her sister at the library, noting it was important to pass on her knowledge to her sister. She was also determined to study hard herself:

... because, you know, you see the lifestyle that you want to have and, you know, not what I've left behind, but sort of what my family has left behind. You think "oh wow I'm so grateful, so I've got to take this opportunity".

In this way, remembering past struggles and a previous lack of opportunities made this young woman appreciate her schooling in a way many young New Zealanders do not. Moreover, the quote indicates that educational investment made in young people from a refugee background benefits not just one individual but potentially the entire family or community. Participant A (who resettled five years ago) took photographs of her brothers in school uniform because:

Schools are a really big part in our family. My Mum and Dad wouldn't be in New Zealand if it wasn't for us and they came here because they wanted a better future for us and we have to do something so we always have to do good in school.

While this quote suggests a sense of responsibility to her parents, she also highlights significant parental expectations of educational success (see Humpage, 2009). Once again, invoking memories of the past led this participant to imagine a future that was grounded in New Zealand and, importantly, might be a means for overcoming collective past trauma and suffering.

While the photographs of the three newest migrants to New Zealand focused most heavily on the absent past, such as commemorating those sacrificed in Eritrea's violent history as discussed in the last section, it is important to acknowledge that they also demonstrated agency in actively 
participating in rituals common in New Zealand, such as the celebration of birthdays with a special cake. Referring to the photograph below (Photo 13), Participant A stated: "[b]irthdays are not that big in our country" but living in New Zealand meant:

... you can't always go with your culture so you have to improvise. Birthdays are really big in here so yeah, even though we don't do it, we don't have parties and stuff, we cut a cake ... You live in New Zealand so you kind of have to go with their culture too.

\section{Photo 13}

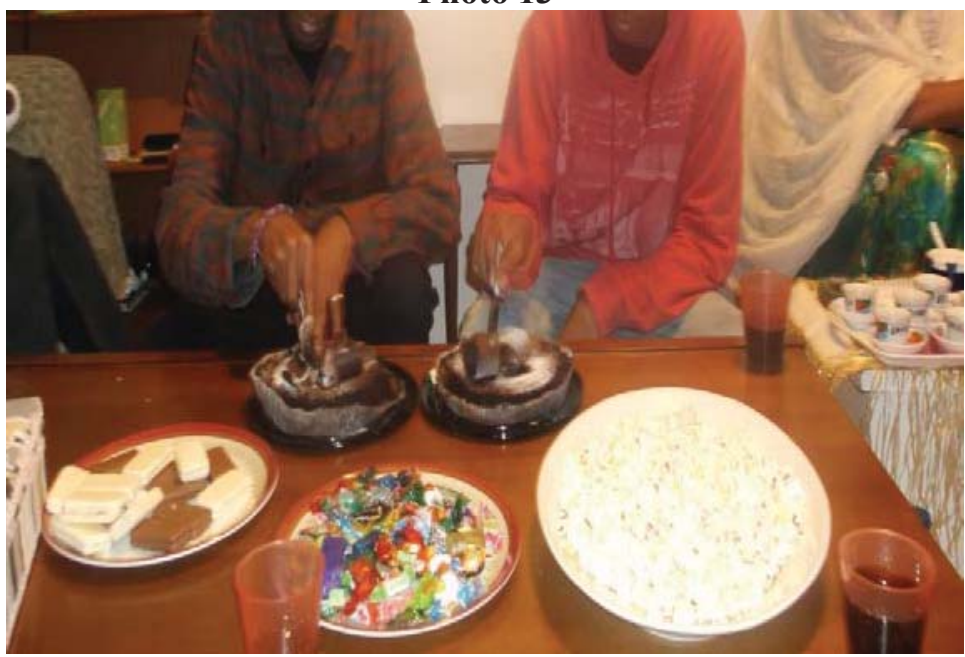

This visual and verbal narrative illustrates the argument that culture is a horizon negotiated within the contexts that people find themselves situated, enabling participants to create new, more positive memories than those associated with the refugee experience. Further evidence is found in photographs of everyday life in New Zealand, which highlight how engaging with 'new' practices in resettlement does not necessitate the exclusion of heritage. Thus, the photographs of the New Zealand-born Participant E saw her reflect on how the local shopping mall is one of her favourite places because she loves fast food and the mall provides a safe and convenient space for socialising with both family and friends. Overall, her photographs - which depicted her sisters and younger relatives eating at well-known fast food restaurants and utilising school holiday 
programmes-demonstrated that she and her family are comfortable moving between not only Eritrean and New Zealand foods but also spaces. Indeed, the participants appeared to illustrate a strong understanding of their 'boundary-crossing' between two cultures. The oldest participant, D, who had lived in New Zealand for ten years, was asked if taking the photos had given her a different perspective on her identity in Auckland. She said:

I haven't been taking anything cultural or anything like that but it made me realise who I am in New Zealand maybe. I'm not back home, I am here and I have to adapt to life in New Zealand and how things go. Back home I wouldn't even have a camera or anything like that, so it just makes me realise a lot of how ... you just become more grateful, kind of like - even my father just says “oh, I've got a car, oh I've got a house".

This woman did participate in an African cultural dance group, noting "I guess you've got to try and please both worlds" and live both in New Zealand and "in Africa". Here she reveals a sophisticated understanding of the situational nature of cultural identity and highlights the incredible flexibility many young people embody as they move back and forth between their 'home' cultures.

As they grew older, our participants were experiencing greater freedoms than they had before. While this period of transition is often theorised as being challenging to identity among young migrants and refugees (Berry et al., 2006), Participant D, for whom this was most relevant, spoke only of the benefits gained as she transitioned to adulthood. Notably, she identified her car and her job as central to her sense of belonging. Indicating the photo below (Photo 14), she said:

I took this photo because my car means a lot to me and that's because I hate public transport very much. My car is like my best friend. It's everywhere with me basically, unless I'm at home then it's outside but other than that me and my car are like buddies ... It's not really the car itself but it's what it does for me.

The car clearly represents a form of independence for this participant. She made a similar statement about work when discussing the photograph below (Photo 15), which is of the retirement village where she had been working part-time for 18 months: "I took this photo because my work is 
like my second home as well. I'm always at work and it's where I eat ... I'm hardly home to have dinner and things so that's my home, second house". She enjoyed working there 20 to 30 hours per week, while also studying, because the residents: "[t]hey're like family to me basically. I don't treat them like residents and whatever. To me-when I'm not at work, they notice that I'm not at work. So it's quite cool'. Here we see how this simple act of recognition — of her absence from work - can have a huge impact upon a young person, particularly one whose refugee experience has been marred by a lack of recognition and respect.

\section{Photo 14}

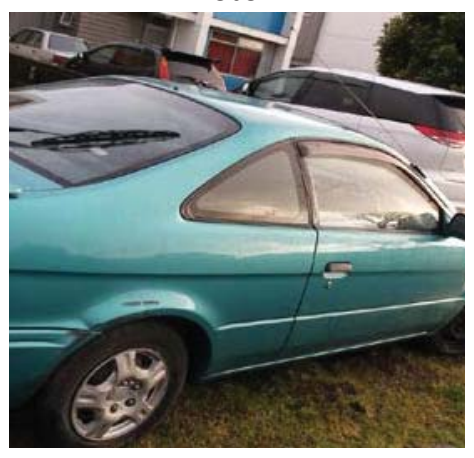

Photo 15

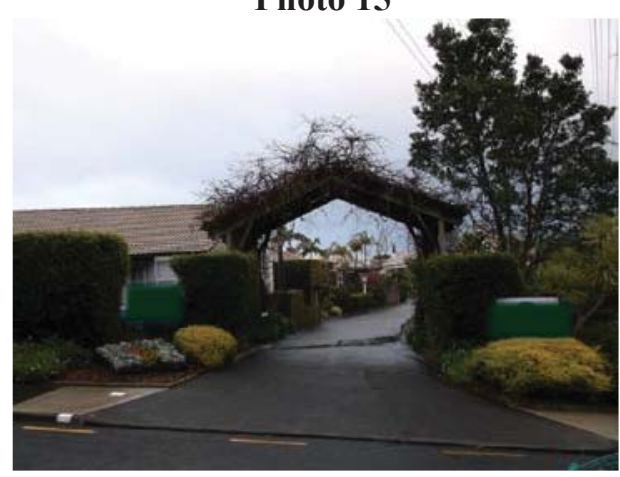

When reflecting on the experience of participating in the Photovoice project, Participant D further noted how she had learned that: "Photos are not just photos, there's something behind photos". Here she referred to how photographs can be used to stimulate old memories, but also how the act of photography itself creates new interpretations of the past, as Participant A also highlighted. For instance, she took the photo of the pedestrian crossing below (Photo 16) because: "Before we came to New Zealand we didn't even know what that was, the pedestrian crossing and allowing the cars to stop for you to walk".

This rather mundane image thus stimulated reflection on the now takenfor-granted life she has created in New Zealand, reminding her of the rapid learning curve young refugees experience upon arrival. Here the second role that memory plays in migration comes into play, offering a 'before' and 'after' comparison that helps overcome the hardships of being transplanted into a new cultural context (Rosińska, 2011). 


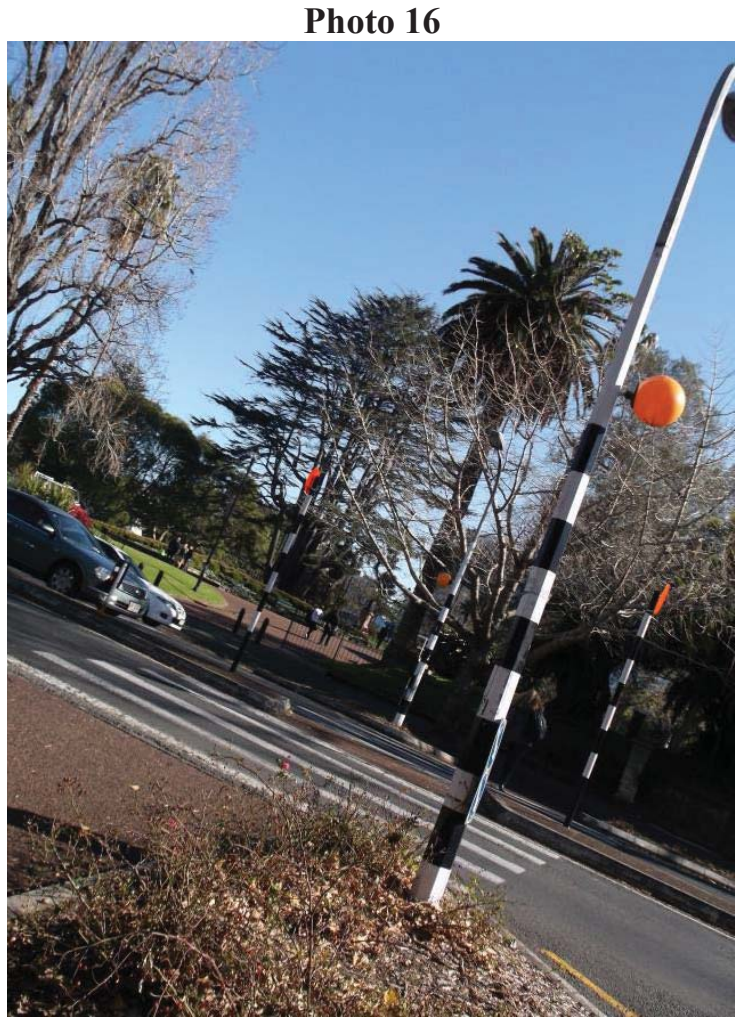

\section{Conclusion: Remembering to belong}

The photographs and narratives of our five Eritrean participants illustrate the importance of memory in creating social connections of two differing kinds (Schacter \& Welker, 2016). First, a collective sense of identity is created or enhanced through 'post-memories' that are not always actually remembered as lived experience by young people from a refugee background but are nonetheless constructed through cultural rituals and symbols centred on food, clothing and decorative homewares, as well as the commemoration of national events that link those born or raised in New Zealand with their Eritrean homeland. The fact that four of five participants chose to focus heavily on these events when taking photographs as part of the Photovoice project suggests that such remembering is an active part of their identity, not just something directed by their parents. This was the case whether participants were New Zealand-born or had migrated. The narrative of the fifth participant indicated that the 'absent' past informed 
her participation in a cultural dance group but even here she placed a greater focus on memories of her own, lived experiences in New Zealand rather than those prior to resettlement. Yet each of the participants took some photographs reminding them of their own lived experiences in New Zealand. These memories highlighted how far they had come since childhood and allowed them to articulate a future in New Zealand - as New Zealanders - that may not have seemed possible earlier.

Second, the data indicated how people's various social locations (gender, age, ethnicity, etc.) intersect with multiple actors, cultural traditions, religious practices and other histories to inform belonging. This is likely true whether a person is a forced or voluntary migrant, but the 'memories' of the nation, may be particularly poignant for individuals from a refugee background, since persecution and dislocation disrupt national and personal histories, even when not personally experienced as in the case of some of our young participants. While caution must be exercised when looking at such a small group of participants, it is clear that living a crossnational and cross-cultural existence led these young women to draw upon both autobiographical and post-memories to develop narratives about who they are.

We recognise that the photographs were taken by participants during a particular life-phase and likely do not represent the multiple ways in which they belong or the ways in which memory is comprehensively conceptualised. The limited time that participants engaged with the researchers also meant that it was impossible to obtain detailed family histories and forced migration experiences to contextualise the accounts of our young participants. The narratives associated with the photographs we selected present, at best, a partial account of their meaning. Nonetheless, the chosen photographs demonstrate the important interplay between past and present in the lives of young refugees. The participants were not 'stuck in the past' or being 'held back' by tradition, but instead demonstrated agency in the ways they negotiated the past and present and the values and traditions important in Eritrea and New Zealand. Photovoice was a useful tool in provoking their stories, largely because of the power of the visual images taken by the young women and their articulate explanations of what they meant to them. We do not deny the challenges the participants have faced and will continue to face in their resettlement journeys, but believe these findings bode well for this generation of young people, who live 'in between' two cultures and two temporal periods. 


\section{References}

Anthias, F., \& Yuval-Davis, Y. (1992). Racialized boundaries: Race, nation, gender, colour and class and the anti-racist struggle. London, UK: Routledge.

Belloni, M. (2016). Refugees as gamblers: Eritreans seeking to migrate through Italy. Journal of Immigrant \& Refugee Studies, 14(1), 104119.

Benhabib, S. (2002). The claims of culture. Princeton, NJ: Princeton University Press.

Berry, J., Phinney, J. S., Sam D. L., \& Vedder, P. (2006). Immigrant youth: Acculturation, identity, and adaptation. Applied Psychology, 55(3), 303-332.

Billig, M. (1995). Banal nationalism. London, UK: Sage.

Bloom, A., O’Donovan, T., \& Udahemuka, M. (2013). "Marking time”: Experiences of successful asylum seekers in Aotearoa New Zealand. Wellington, NZ: ChangeMakers Refugee Forum.

Brough, M., Gorman, D., Ramirez, E., \& Westoby, P. (2003). Young refugees talk about well-being: A qualitative analysis of refugee youth mental health from three states. Australia Journal of Social Issues, 38(2), 193-208.

Carlson, E. D., Engebretson, J., \& Chamberlain, R. M. (2006). Photovoice as a social process of critical consciousness. Qualitative Health Research, 16(6), 836-852.

Connell, D., \& Killion, T. (2011). Historical dictionary of Eritrea (2 ed.). Plymouth, UK: Scarecrow Press.

Dirar, U. C. (2007). Colonialism and the construction of national identities: The case of Eritrea. Journal of Eastern African Studies, 1(2), 256276.

D'Sylva, A., \& Beagen, B. (2011). 'Food is culture, but it's also power': The role of food in ethnic and gender identity construction among Goan Canadian women. Journal of Gender Studies, 20(3), 279-289.

Fiddian-Qasmiyeh, E. (2013). The inter-generational politics of 'travelling memories': Sahrawi refugee youth remembering home-land and home-camp. Journal of Intercultural Studies, 34(6), 631-649.

Fozdar, F., \& Hartley, L. (2012). Refugees in Western Australia: Settlement and integration. Perth, WA: Metropolitan Migrant Resource Centre/University of Western Australia.

Graf, S., \& Thieme, S. (2016). 'We look similar and have the same geographical origin': Translocal encounters of second-generation 
Eritreans with a new generation of refugees from Eritrea. Geographica Helvetica, 71(4), 331-340.

Green, E., \& Kloos, B. (2009). Facilitating youth participation in a context of forced migration: A Photovoice project in Northern Uganda. Journal of Refugee Studies, 22(4), 460-482.

Halilovich, H. (2011). Beyond the sadness: Memories and homecomings among survivors of 'ethnic cleansing' in a Bosnian village. Memory Studies, 4(1), 45-52.

Hirsch, M. (1999). Projected memories: Holocaust photographs in personal and public fantasy. In M. Bal, J. Crewe \& L. Spitzer (Eds.), Acts of memory: Cultural recall in the present (pp. 3-23). Hanover: Dartmouth College, University Press of New England.

Hoyle, P. (1999). The Eritrean national identity: A case study. North Carolina Journal of International Law and Commercial Regulation, 24, 381-416.

Human Rights Watch. (2015). World report 2015. www.hrw.org/worldreport $/ 2015$

Humpage, L. (2000). Embodying ambiguity: Somali refugee women and ethnic boundary 'maintenance'. Women's Studies Journal, 16(2), 929.

Humpage, L. (2009). A 'culturally unsafe' space? The Somali experience of Christchurch secondary schools. New Zealand Geographer, 65(1), 73-82

Mannik, L. (2013). Photography, memory and refugee identity: The voyage of the SS Walnut, 1948. Vancouver: UBC Press.

Norwegian Refugee Council. (2004). Profile of internal displacement: Ethiopia. Geneva: Norwegian Refugee Council.

Raffaetà, R., Baldassar, L., \& Harris, A. (2016). Chinese immigrant youth identities and belonging in Prato, Italy: Exploring the intersections between migration and youth studies. Identities, 23(4), 422-437.

Reporters Without Borders. (2016). 2016 World Press Freedom Index Leaders paranoid about journalists. https://rsf.org/en/news/2016world-press-freedom-index-leaders-paranoid-about-journalists

Rosińska, Z. (2011). Emigratory experience: The melancholy of no return. In J. Creet \& A. Kitzmann (Eds.), Memory and migration: Multidisciplinary approaches to memory studies (pp. 29-42). Toronto: University of Toronto Press.

Schacter, D., \& Welker, M. (2016). Memory and connection: Remembering the past and imagining the future in individuals, groups and cultures. Memory Studies 9(3), 241-244. 
Somerville, K. (2008) Transnational belonging among second generation youth: Identity in a globalized world. Journal of Social Sciences Special Volume 10, 23-33.

Statistics New Zealand. (2013). Census ethnic group profiles: Eritrean. http://www.stats.govt.nz/Census/2013-census/ profile-and-summaryreports/ethnic-profiles.aspx?request value $=24791 \&$ tabname $=$ Keyfacts

Triandafyllidou, A. (1998). National identity and the "other". Ethnic and Racial Studies, 21(4), 593-612.

United Nations High Commissioner for Refugees. (1951). Convention and protocol relating to the status of refugees. www.unchr.org/ 3b66c2aa10.html

Wang, C. (2006). Youth participation in Photovoice as a strategy for community change. Journal of Community Practice, 14(1-2), 147161.

Yuval-Davis, N. (2011). The politics of belonging: Intersectional contestations. London, UK: Sage. 